\title{
Ações de Didatização de Gêneros em prol de Letramentos Acadêmicos: práticas e demandas ${ }^{1}$
}

\author{
Vera Lúcia Lopes Cristovão² \\ Jacqueline Costa Sanches Vignoli ${ }^{3}$
}

\section{Resumo}

Todos os anos, novos estudantes ingressam no Ensino Superior e são demandados a desempenhar ações, em língua portuguesa e em línguas estrangeiras, ou seja, os alunos são inseridos em práticas linguageiras denominadas letramentos acadêmicos. Neste artigo, objetivamos apresentar as linhas mestras de um projeto interinstitucional desenvolvido por pesquisadores de três universidades públicas paranaenses (UEL, UTFPR e UNESPAR), cujo objetivo central é o de mapear a existência e/ou as possíveis demandas por práticas de Letramentos acadêmicos no Ensino Superior para, na sequência, propor ações didáticas conjuntas nas universidades envolvidas em um processo de implementação do Laboratório Integrado de Letramentos Acadêmicos - LILA. Como conclusão, apontaremos alguns desafios encontrados na pesquisa, bem como algumas possibilidades de resolução das dificuldades.

Palavras-chave: Letramentos acadêmicos; Pesquisa em rede; Ações didáticas.

\section{Pedagogical approach actions towards academic literacies: practices and requirements}

\section{Abstract}

Every year new students get into higher education and are required to perform actions in Portuguese and in foreign languages, that is, students are engaged in language practices related to academic literacies. In this text, our objective is to present the main structure of an interinstitutional project developed by researchers of three public universities from the state of Paraná (UEL, UTFPR e UNESPAR), whose first phase aims at mapping the existence and/or requirements of academic literacy practices in higher education in order to propose, in the next phase, joint pedagogical actions in the universities involved in a process of implementing our Academic Literacies Integrated Laboratory - LILA. Finally, to conclude our text, we point out some challenges we have faced in our study as well as some possibilities of overcoming such difficulties.

Keywords: Academic literacies; Research in a network; Pedagogical actions

\section{Considerações iniciais}

\section{O Senso da Educação Superior é realizado todos os aos pelo INEP4 e tem como objetivo} oferecer à população em geral informações sobre a situação do ensino superior no Brasil. De

\footnotetext{
${ }^{1}$ Pesquisa conta com financiamento do CNPq para o Projeto "Ações de didatização de gêneros em prol de letramentos acadêmicos", por meio da Chamada CNPq № 09/2018, Processo: 310413/2018-4, com bolsa de produtividade em pesquisa para a primeira autora.

${ }^{2}$ UEL/CNPq, Universidade Estadual de Londrina, Londrina, PR, veraluciacristovao@gmail.com

${ }^{3}$ UNESPAR/UEL, Universidade Estadual do Paraná, Campo Mourão, PR. Artigo relacionado ao projeto em andamento de pós-doutoramento Letramentos acadêmicos no ensino superior público paranaense: a graduação da Unespar em foco, sob orientação da Profa. Dra. Vera Lucia Lopes Cristovão. jacqueline.vignoli@unespar.edu.br

${ }^{4} \mathrm{O}$ INEP, Instituto Nacional de Estudos e Pesquisas Educacionais Anísio Teixeira, realiza anualmente o Censo da Educação Superior com informações sobre as instituições de ensino superior que ofertam cursos de graduação e/ou sequenciais. Mais informações em: http://inep.gov.br/censo-da-educacao-superior
}

Periódico Horizontes - USF - Itatiba, SP - Brasil - e020012 
acordo com dados estatísticos apresentados, em 15 anos (entre os anos de 2002 e 2017), o número de matrículas em cursos de graduação no ensino superior (público e privado) saltou de 1.411.208 para 8.286.663, um aumento de quase 600\%. Apenas no estado do Paraná, em 2002, 98.565 estudantes ingressaram em cursos de graduação, sendo que o número, em 2017, chegou a 519.398 matrículas.

O breve esboço estatístico apresentado serve para comprovar um fato: a intensa expansão do ensino superior público brasileiro vivida nos últimos anos. No bojo do aumento do número de universitários (e muito provavelmente em consequência dele), uma área de pesquisa tem demonstrado grande vigor: o campo de estudos dos letramentos acadêmicos, lócus a que esta pesquisa está vinculada. Fiad (2011, p. 362) afirma que

Boa parte das pesquisas sobre letramentos acadêmicos surge a partir da observação das escritas de estudantes oriundos de diferentes classes sociais e etnias. Ao entrarem na universidade, os estudantes são requisitados a escreverem diferentes gêneros, com os quais não estão familiarizados em suas práticas de escrita em outros contextos (inclusive escolar) e são mal avaliados por seus professores. Na verdade, como apontam autores (LEA e STREET, 1998; JONES, TURNER e STREET, 1999) começam a ficar visíveis os conflitos entre o que os professores esperam das escritas e o que os alunos escrevem. Ou seja, não há correspondência entre o Letramento do estudante e o Letramento que Ihe é exigido na universidade.

Refutando o "discurso da crise" e afirmando que não se pode mais ver a leitura e a escrita como habilidades individuais, Fiad (2011, p. 360) defende a perspectiva de entendimento das práticas de leitura e de escrita sempre em sua relação específica com um dado contexto sóciohistórico-cultural, de modo que os estudantes sejam vistos como sujeitos letrados que "não se engajaram ainda nas práticas letradas esperadas no contexto acadêmico".

Corroboramos a visão de Fiad (2011), entendendo que as práticas de leitura e de escrita na academia não podem ficar reduzidas ao discurso do déficit, com a constatação, por parte dos professores do ensino superior, de que "os estudantes chegam à universidade em saber escrever". Nesse sentido, entendemos como urgente a promoção de pesquisas sobre as ações de letramentos acadêmicos promovidas pelas instituições de ensino superior com vistas ao mapeamento do que está sendo feito para que, se for o caso, outras formas de práticas possam ser desenvolvidas. 
As discussões sobre leitura e escrita no ensino superior fazem emergir muitas questões a elas relacionadas, por exemplo: as dificuldades dos alunos (graduandos e pós-graduandos) na produção de textos acadêmicos; as escolhas didático-metodológicas para realizar um trabalho de leitura e escrita consistente no Ensino Superior; as concepções de alunos e professores sobre letramentos acadêmicos; o espaço e tempo específicos para pesquisa e práticas de letramentos acadêmicos nos currículos de cursos e programas; a formação para a escrita e por meio da escrita; a escrita profissional; a formação para os gêneros orais como apresentações de seminários e de comunicações em eventos, entre outras.

Para tanto, neste artigo, apresentamos as linhas mestras de um projeto interinstitucional desenvolvido por pesquisadores de três (até o momento) universidades públicas paranaenses, cujo objetivo central é o de mapear, nesta fase inicial, a existência e/ou as possíveis demandas por práticas de letramentos acadêmicos no Ensino Superior para, na sequência, propor ações didáticas conjuntas nas universidades envolvidas em um processo de implementação do Laboratório Integrado de Letramentos Acadêmicos - LILA. Assim, apresentaremos os conceitos de letramentos, letramentos acadêmicos e capacidades de linguagem, pertinentes ao desenvolvimento da pesquisa; na sequência discorremos sobre o percurso de pesquisa projetado e, por fim, teceremos algumas considerações sobre os primeiros desafios e possíveis ações para superá-los neste início de pesquisa.

\section{Breve revisão de literatura sobre letramentos e letramentos acadêmicos ${ }^{5}$}

As teorias dos letramentos despontaram no Brasil a partir da década de 90 e, somadas às teorias linguísticas já utilizadas para análise de escritas de estudantes de diversos contextos escolares, constituíram um importante campo de pesquisa. Fiad (2016, p. 203) define letramentos como "prática social, dependente dos contextos sociais nos quais a língua escrita se inscreve" e explica que a abordagem chamada de Novos Estudos do Letramentos (NEL) (STREET, 1984) opõe-se às perspectivas teórica que atribuíam supremacia à escrita, estabelecendo um

\footnotetext{
${ }^{5}$ Neste artigo, utilizaremos os termos letramentos e letramentos acadêmicos no plural por corroborarmos a compreensão de que não há apenas um tipo de letramento, mas vários tipos relacionados à diversas práticas de interação social.
}

Periódico Horizontes - USF - Itatiba, SP - Brasil - e020012 
posicionamento dicotômico e valorativo entre oralidade e escrita. Na visada dos NEL, tanto a escrita quanto a leitura passam a ser vistos como processos relacionados a aspectos culturais, históricos e sociais, uma vez que os letramentos são sempre múltiplos, a depender dos significados atribuídos pelos diferentes agrupamentos humanos.

Street (2014, p. 38) discorre sobre dois modelos para compreensão dos letramentos: o modelo autônomo e modelo ideológico. O primeiro está calcado em uma percepção homogênea de letramentos, pautado na teoria da "grande divisão" entre letrados e iletrados, conforme reproduzimos no quadro abaixo:

Quadro 1 Diferenças entre "letrados" e "iletrados", de acordo com o modelo autônomo de letramentos.

\begin{tabular}{|l|l|l|}
\hline Planos & Letrados & lletrados \\
\hline Individual & $\begin{array}{l}\text { Modos de raciocínio } \\
\text { Capacidades cognitivas } \\
\text { Facilidade com lógica } \\
\text { Abstração e operações mentais } \\
\text { superiores. }\end{array}$ & $\begin{array}{l}\text { Não conseguem pensar abstratamente } \\
\text { Mais passivos e menos críticos } \\
\text { Menos capazes de refletir sobre a natureza da língua ou } \\
\text { sobre as fontes de sua opressão política }\end{array}$ \\
\hline Social & $\begin{array}{l}\text { Avanço econômico } \\
\text { Progresso social } \\
\text { Benefícios da modernização }\end{array}$ & $\begin{array}{l}\text { Atraso econômico } \\
\text { Pouca participação da ordem econômica mundial } \\
\text { Pouca mobilidade social. }\end{array}$ \\
\hline
\end{tabular}

Fonte: STREET, 2014.

O segundo modelo, entretanto, questiona a teoria da "grande divisão" entre sujeitos e sociedades "letrados(as)" e "iletrados(as)", uma vez que Street (2014, p. 41) afirma que "o Letramento em si mesmo não promove avanço cognitivo, a mobilidade social ou o progresso: práticas letradas são específicas ao contexto político e ideológico e suas consequências variam conforme a situação". Isso não significa, reforça o autor, abandonar os esforços para difusão das práticas de letramentos, mas de, a partir de outras concepções, abandonar a percepção equivocada de relação unidirecional entre letramento/alfabetização e progresso social, econômico e cultural. Nesse sentido, sobre o modelo ideológico, Street resume:

[...] um quadro teórico que postula a existência de uma variedade de letramentos em diferentes contextos, nenhuma separação entre letrado e iletrado, e uma gama de habilidades cognitivas e sociais associadas igualmente à oralidade e ao letramento, então a agenda muda e o estigma (aos iletrados) fica sem sentido. Todos na sociedade exibem alguma dificuldade de letramento em alguns contextos (STREET, 2014, p. 41). 
Assim, a definição de Street $(2010,2014)$ para letramentos engloba o uso da linguagem escrita como prática social articulada ao entorno sócio-histórico-cultural e ao uso de tecnologias para propósitos específicos. A partir dessa caracterização, criaram-se desdobramentos conceituais, cada um com uma função, para atender diferentes necessidades da sociedade e relacionados a diferentes domínios ou sistemas de atividades. Assim, os letramentos estão integrados ao agir/à prática social, já que, para agir, o indivíduo pode utilizar diferentes recursos multissemióticos, dependendo da situação de comunicação em que se encontra inserido.

Com relação à concepção de letramentos como "conjunto de práticas sociais situadas", Fiad (2016, p. 205) explica que alguns teóricos começaram a nutrir interesse pelo contexto acadêmico "com o objetivo de compreender as práticas aí presentes, compreendendo que há práticas específicas desse contexto, dada a concepção de múltiplos letramentos". Nesse sentido, pesquisas como de Lea e Street $(1998,2014)$ e Street $(2010)$ demonstram interesse pela escrita no ensino superior, cunhando uma abordagem de estudos chamada de letramentos acadêmicos.

O campo de estudo dos letramentos acadêmicos é promissor por dois motivos essencialmente, de acordo com Rinck, Boch e Assis (2015): o primeiro refere-se às dificuldades enfrentadas pelos estudantes com relação à escrita no ensino superior. O segundo motivo diz respeito à assunção, por parte das teorias dos letramentos, de que a entrada na universidade não significa que o processo de aprendizagem da escrita esteja concluído. Nesse sentido, as pesquisadoras afirmam que: “A aprendizagem da escrita não está concluída quando da entrada na universidade. Não se trata apenas de aprender a ler e escrever em situações diferentes e em evolução, mas também de aprender a pensar e a agir por meio da escrita" (RINCK; BOCH; ASSIS, 2015, p. 11).

O que Rinck, Boch e Assis (2015) apontam tem relação com aquilo a que Lea e Street $(1998,2014)$ denominam "discurso do déficit", ou seja, quando há o entendimento de que o ingresso na universidade pressupõe a conclusão da aprendizagem da escrita, as escritas dos estudantes são avaliadas a partir daquilo que falta para que cumpram as expectativas do que seriam textos próprios da esfera acadêmica.

Quanto ao termo letramentos acadêmicos, a noção foi desenvolvida na área dos Novos 
Estudos do Letramentos ${ }^{6}$ (STREET, 1984; BARTON; HAMILTON, 1998; GEE, 1996), numa visão sociocultural dos usos da escrita e da leitura como práticas sociais contextualizadas. No desenvolvimento dos letramentos acadêmicos, as questões de escrita e aprendizagem no ensino superior implicam novas formas de compreensão e interpretação do conhecimento (LEA; STREET, 1998). É necessário incluir nos currículos e na pesquisa práticas nas quais o aluno possa se familiarizar e aprender a ler e a escrever gêneros dessa comunidade discursiva.

Abordando os novos conceitos de letramentos propostos por Lea e Street (2014), a noção de letramentos acadêmicos demonstra que a escrita do estudante universitário pode ser compreendida por três prismas, sendo esses reconhecidos como habilidades de estudo, socialização acadêmica e letramentos acadêmicos. Esses não são mutuamente exclusivos, mas sobrepostos, podendo ser aplicáveis em todo contexto acadêmico.

O modelo das habilidades de estudo está concentrado nos aspectos de habilidade individual e cognitiva de leitura e escrita e no conhecimento de estruturas formais da língua. Nessa perspectiva, o histórico de letramentos que o aluno traz consigo não é considerado, fazendo com que a responsabilidade de desenvolvimento das competências de leitura e escrita seja de sua inteira responsabilidade.

Para Lea e Street (2014), na abordagem da escrita como socialização acadêmica, o professor é responsável pela socialização do aluno no contexto universitário, relacionando-se com a aculturação de discurso e gêneros. Esse modelo se volta, também, para a questão da produção de gêneros acadêmicos para fins de avaliação, em que as práticas textuais realizadas pelos alunos servem para testar, de certo modo, o nível de compreensão atingido por eles em situações e contextos isolados, como no momento da realização de provas ou trabalhos.

O modelo de letramentos acadêmicos está relacionado a questões de identidade, poder, autoridade e produção de sentido. Nessa abordagem, a história de letramentos do aluno é considerada, bem como sua aculturação ao discurso da nova comunidade discursiva em que está inserido. Essa inserção por meio de sua participação social é que constitui suas práticas de letramentos acadêmicos.

Lea e Street (2014) mencionam ainda que os modelos de letramentos acadêmicos fazem

\footnotetext{
${ }^{6}$ Em inglês, New Literacy Studies.
} 
[...] uso do modelo de habilidades e de socialização acadêmica, mas vai além do modelo de socialização acadêmica, por exemplo, ao dispensar particular atenção às relações de poder, autoridade, produção de sentido e identidade, implícitas no uso de práticas de letramentos em quadros institucionais específicos. Esse modelo não concebe as práticas de letramentos como completamente restritas às disciplinas e às comunidades temáticas; examina, também, como as práticas de letramentos advindas de outras instâncias (por exemplo, governamental, empresarial, da burocracia universitária) estão comprometidas com aquilo que os estudantes precisam aprender e fazer (LEA; STREET, 2014, p. 481).

Os letramentos acadêmicos não vão cuidar apenas das temáticas trabalhadas nas disciplinas, mas de todo o contexto que uma pessoa precisa saber/conhecer dentro da academia. As ações de ler um texto, escrever um artigo, desenvolver a fala para apresentações orais e até mesmo formular um pensamento crítico podem propiciar a busca de novos saberes para implementar os conhecimentos adquiridos por meio de outros tipos de letramentos. No contexto universitário, os alunos podem aprender a produzir uma diversidade de textos, além de lerem textos de gêneros diversos.

Como práticas de comunicação podem variar de acordo com as disciplinas e gêneros, o estudante precisa ser inserido no domínio acadêmico e em práticas de socialização desse discurso. O desenvolvimento desses letramentos engloba reconhecer a constituição dos gêneros, maneiras de ser, agir, valorizar e a utilizar recursos na produção de conhecimento científico para uma área específica

Dessa forma, é necessário que o meio universitário desenvolva formas para complementar o processo de letramentos a fim de formar, transformar e/ou completar a educação de forma crítica. Na perspectiva de Rinck, Silva e Assis (2012),

[a] formação para a leitura e a escrita e por meio da leitura e da escrita, na universidade e na vida profissional, poderá, portanto, se fundar nos princípios e objetivos seguintes: (i) cobrir todas as dimensões da escrita e da leitura, da ortografia e gramática até o uso de variados gêneros (tendo em vista tanto os formatos de texto quanto as questões que dizem respeito aos conteúdos temáticos), (ii) servir de fio condutor da formação acadêmica às esferas profissionais, passando pelas especificidades disciplinares e tendo em conta também outros usos sociais (por exemplo, leitura de obras literárias, fóruns na internet, etc.) (iii) promover o desenvolvimento do letramento, mas experienciando o letramento como uma forma de pensar e agir, como um lugar de construção do conhecimento (na universidade, no trabalho, na sociedade do conhecimento) e como um espaço de autoconstrução (identidade profissional, desenvolvimento

Periódico Horizontes - USF - Itatiba, SP - Brasil - e020012 
pessoal, capacitação e mesmo emancipação em alguns programas educativos inspirados por Dewey, 1916) (RINCK; SILVA; ASSIS, 2012, p. 11-12).

Em relação ao trabalho com gêneros acadêmicos no Ensino Superior, Marinho (2010) defende que "[...] na instituição e nas esferas do conhecimento em que são constituídos, portanto, quando se inserem nas práticas de escrita universitária [...] parece necessário incluir esse conteúdo nos currículos e nas pesquisas" (MARINHO, 2010, p. 366). Trabalhos investigativos acerca de questões de letramentos como as dificuldades de estudantes na produção textual de gêneros relacionados à esfera acadêmica (FISCHER; 2010, MOTTA-ROTH; HENDGES, 2010; MARINHO, 2010; FIAD, 2011) parecem revelar a impossibilidade de simples transferência dos letramentos obtidos durante o processo de escolarização e reforçar a necessidade de um trabalho específico voltado para os letramentos acadêmicos. Para atender a essa demanda, as obras de Machado, Lousada e Abreu-Tardelli (2004a, 2004b, 2005a, 2005b, 2007) e Motta-Roth e Hendges (2010) estão voltadas para a didatização de gêneros textuais acadêmicos.

No caso da coleção Leitura e Produção de Textos Técnicos e Acadêmicos, as autoras Machado, Lousada e Abreu-Tardelli desenvolvem uma proposta didática com base no Interacionismo Sociodiscursivo (ISD) voltado para o desenvolvimento de capacidades de linguagem. As capacidades de linguagem são apresentadas por Dolz, Pasquier e Bronckart (1993, p. 30) como "aptidões requeridas para a realização de um texto numa situação de interação determinada". Em sua proposta original, elas seriam de três tipos: capacidades de ação, capacidades discursivas e capacidades linguístico-discursivas.

As capacidades de ação se constituem pela faculdade/possibilidade de a pessoa construir conhecimentos e/ou representações sobre o contexto de produção de um texto, o que pode contribuir para seu reconhecimento do gênero e sua adequação à situação de comunicação. Já as capacidades discursivas possibilitam a mobilização de conhecimentos e/ou representações sobre a organização do conteúdo em um texto e sua apresentação. Finalmente, as capacidades linguístico-discursivas se constituem por conhecimentos e/ou representações que um indivíduo constrói sobre as operações e os recursos de linguagem necessários para a produção ou compreensão de um texto (DOLZ; SCHNEUWLY, 1998). As capacidades de linguagem supracitadas parecem evidenciar os planos da atividade de linguagem, da ação linguageira em uma situação de comunicação específica e do texto propriamente dito. 
Em virtude da necessidade de evidenciar aspectos mais amplos em termos de atividade geral, de conjuntos e sistemas de gêneros, bem como de uma contribuição marcada para o quadro de intervenção didática para produção e compreensão de textos na aprendizagem de línguas (em especial, língua estrangeira), a proposta de capacidades de significação foi apresentada. Em Cristovão e Stutz (2011), defende-se que

(...) as capacidades de significação (CS) possibilitam ao indivíduo construir sentido mediante representações e/ou conhecimentos sobre práticas sociais (contexto ideológico, histórico, sociocultural, econômico etc) que envolvem esferas de atividade, atividades praxiológicas em interação com conteúdos temáticos de diferentes experiências humanas e suas relações com atividades de linguagem (CRISTOVÃO; STUTZ, 2011, p. 22-23).

A proposta das capacidades de significação ancora-se na visão de proporcionar róis de possibilidades de interpretação/compreensão e ação em suas relações dinâmicas e interdependentes com sua rede. Outra justificativa importante para o conceito é a recorrência de tarefas em materiais e em práticas didáticas de tarefas de busca de informação desses elementos, sem aprofundar nas relações dessas informações com a produção de significação. Ou seja, algumas atividades didáticas sugerem que o aluno busque dados como: quem produziu um determinado texto, para quem, quando, como, onde e para quê e são concluídas como se as respostas automaticamente deflagrassem no leitor/no aluno uma reflexão sobre ideologia(s) subjacente(s), relações de poder, traços culturais daquela determinada prática social etc. Ademais, o espaço dedicado a atividades para o desenvolvimento de capacidades de significação privilegia a compreensão de sistema(s) de gêneros e de conjuntos de gêneros que constituem atividades que envolvem, por exemplo, a leitura e a escrita.

No quadro teórico-metodológico do ISD, o procedimento didático proposto é o da sequência didática, composta de atividades organizadas em torno de (um sistema) de gênero(s), voltadas às capacidades de linguagem necessárias para o agir por meio desse(s) gênero(s) em uma prática social.

Outras perspectivas didáticas para letramentos acadêmicos propõem outros dispositivos ou abordagens. Dudley-Evans (1995), por exemplo, relata uma abordagem composta de análises de gênero e ensino cooperativo conciliado à instrução de linguagem acadêmica, à docência em time na área disciplinar específica e a sessões de monitoria e revisão 
da produção escrita com a participação de pós-graduandos.

O estudo de Murray e Glass (2011) sobre desenvolvimento da aprendizagem no Ensino Superior analisou cinquenta e seis respostas a duas enquetes feitas em universidades da GrãBretanha. Dois resultados relatados são: i) dois serviços comumente mencionados são as oficinas e as monitorias; ii) as monitorias são consideradas centrais para o desenvolvimento. Ressaltamos a relação entre esses resultados e as propostas de oficinas e monitorias implementadas em diferentes laboratórios como o da USP, por exemplo. ${ }^{7}$

Tendo em vista a problemática descrita e a anuência com propostas voltadas aos letramentos acadêmicos, consideramos pertinente e urgente a formação de um Laboratório Integrado de Letramentos Acadêmicos - LILA no qual diferentes IES possam participar e delas se beneficiarem, já que as tecnologias digitais permitem essa colaboração.

\section{Desenho da pesquisa: breve descrição}

Pautada em uma perspectiva de pesquisa em rede, o projeto Ações de Didatização de Gêneros em prol de Letramentos Acadêmicos conta, inicialmente, com pesquisadores de três universidades ${ }^{8}$ públicas paranaenses, localizadas em diversas regiões do Estado: Universidade Estadual de Londrina (UEL), Universidade Tecnológica Federal do Paraná (UTFPR) e Universidade Estadual do Paraná (UNESPAR).

A Universidade Estadual de Londrina (UEL), sediada no município de Londrina, no norte do Paraná, conta com 53 cursos presenciais de Graduação (bacharelados e licenciaturas) e 261 de Pós-Graduação (residências, especializações, mestrados e doutorados), com uma comunidade formada por 25 mil estudantes, professores e servidores técnico-administrativos. A Universidade Tecnológica Federal do Paraná (UTFPR) oferece 100 cursos superiores de tecnologia, bacharelados e licenciaturas. O número de estudantes regulares passa de 32 mil,

\footnotetext{
7 Laboratório de Letramento Acadêmico da Universidade de São Paulo foi criado de 2011 com a motivação "da universidade de preparar os alunos para novos contextos de comunicação na qual a língua materna e estrangeira convivem e o registro escrito é fundamental para a divulgação do conhecimento acadêmico" (FERREIRA; LOUSADA, 2016, p.129).

${ }^{8}$ Atualmente estamos em tratativas com pesquisadores de mais quatro universidades com vistas à ampliação da rede e da área de abrangência do projeto.
}

Periódico Horizontes - USF - Itatiba, SP - Brasil - e020012 
distribuídos em 13 campi distribuídos em todo o estado. Por fim, a Universidade Estadual do Paraná (UNESPAR) tem característica multicampi e possui cerca de 12 mil estudantes em seus sete campi, matriculados em 68 cursos de graduação e de pós-graduação. A figura 1 apresenta a área de abrangência das três universidades envolvidas inicialmente no projeto:

Figura 1 Mapa das universidades participantes do projeto Ações de Didatização de Gêneros em prol de Letramentos Acadêmicos

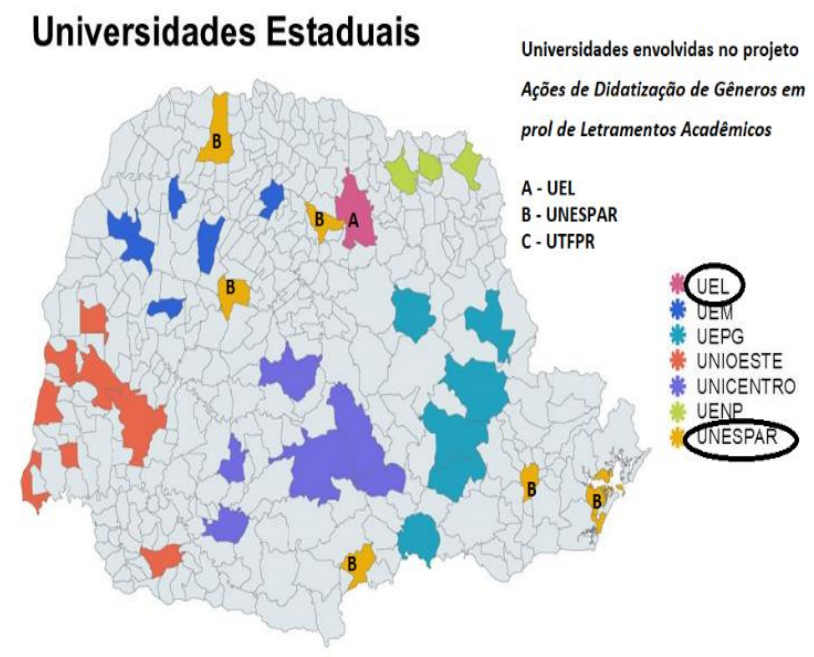

\section{Universidades Federais}

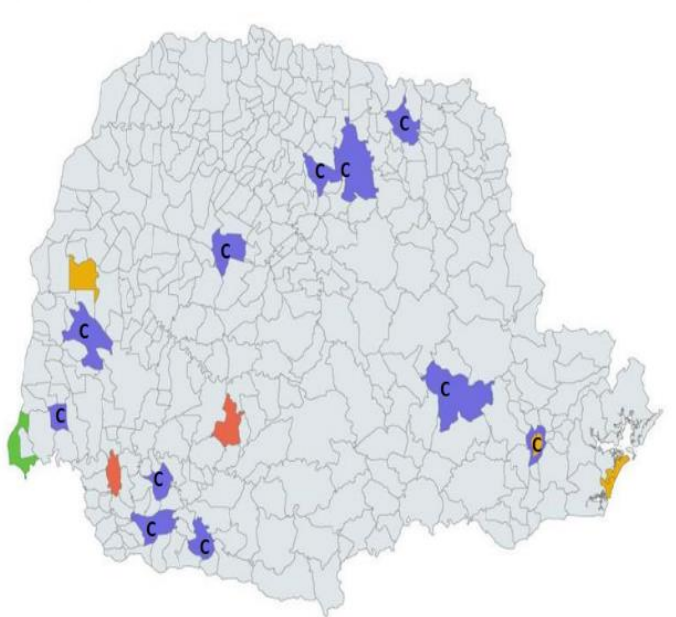

Fonte: Superintendência Geral de Ciência, Tecnologia e Ensino Superior do Paraná (SETI). Adaptado

A pesquisa é organizada para ser desenvolvida em fases, a partir de uma proposta metodológica de método misto sequencial exploratório. O método misto é definido como "pesquisa na qual o investigador coleta e analisa dados, integra os resultados e faz inferências usando tanto abordagens ou métodos qualitativos quanto quantitativos em um único estudo ${ }^{9 \prime \prime}$ (TASHAKKORI; CRESWELL, 2007, p. 4). Para isso, propomos o desenvolvimento da pesquisa em fases que compõem um método sequencial exploratório de coleta e geração de dados e análise.

De acordo com o desenho da pesquisa, a primeira etapa ${ }^{10}$ é a de levantamento de práticas desenvolvidas e de demandas didáticas em prol de letramentos acadêmicos nas universidades contempladas em nosso escopo. Para tanto, dois instrumentos foram propostos: questionários

\footnotetext{
9 "research in which the investigator collects and analyzes data, integrates the findings and draws inferences using both qualitative and quantitative approaches or methods in a single study" (TASHAKKORI; CRESWELL, 2007, p. 4). ${ }^{10}$ Instrumentos de coleta de dados (questionários) aprovado pelo Comitê de Ética em Pesquisa sob número de CAAE 09695319.4.1001.5231, Parecer: 3.270.217.
} 
online e análise de ementas das disciplinas presentes em cursos de graduação e de pós-graduação.

Compreendemos que esta etapa, inicial e deflagradora das fases seguintes, seja essencial, uma vez que proporcionará uma percepção mais abrangente dos diferentes contextos envolvidos. Assumimos, portanto, que anterior ao processo de implementação de ações, faz-se primordial a compreensão das demandas e das expectativas com relação às ações didáticas para letramentos acadêmicos, pois, do contrário, poderíamos incorrer em modelos de letramentos que, em resposta ao discurso do déficit, postulam a existência de uma cultura acadêmica homogênea, um conteúdo universal de aprendizagem, como afirmam Pasquotte-Viera e Fiad (2015).

Os questionários foram compostos com perguntas orientadas a partir de dois eixos: ações conhecidas e ações desejadas. Os questionários contemplam três setores das universidades: a gestão universitária (pró-reitores, diretores de centros, chefes de divisão), coordenadores de colegiados de cursos de graduação e de programas de pós-graduação e estudantes matriculados nos últimos anos dos cursos de graduação. Nossos intuitos, nesta fase inicial, são especialmente: a) perceber, a partir das respostas, quais as representações/modelos sobre letramentos acadêmicos mais recorrentes e b) realizar um levantamento das necessidades apontadas pelos informantes.

Com vistas à compreensão do teor das perguntas formuladas para a primeira etapa, o Quadro 2 reproduz o questionário destinado aos coordenadores de cursos de graduação das três universidades, embora haja questionários diferentes ${ }^{11}$ para cada um dos segmentos (coordenadores, gestores e acadêmicos) consultados.

Quadro 2 - Questionário para coleta de ações e demandas sobre letramentos acadêmicos dos cursos de graduação

\section{QUESTIONÁRIO PARA COORDENADORES DE CURSO DE GRADUAÇÃO}

Conhece alguma(s) experiência(s) didática(s) em prol de Letramentos acadêmicos, em LíNGUA PORTUGUESA, destinada(s) aos estudantes do curso de graduação coordenado por você (pode incluir iniciativas em conjunto como outras universidades)

Se respondeu SIM na questão anterior (questão 01), quais são as experiências relativas aos Letramentos acadêmicos que ocorrem no curso de graduação coordenado por você (incluindo iniciativas conjuntas com outras instituições) Marque todas as que se aplicam.

Cursos/disciplinas para estudantes de primeiro ano

Cursos/disciplinas para estudantes após o primeiro ano

Tutoriais

Centros de escrita / Laboratórios de escrita acadêmica

Programas articulados que incluem uma ou mais dessas iniciativas

Outro

\footnotetext{
${ }^{11}$ Os questionários são diferentes para abarcar as especificidades de demandas de cada um dos setores consultados.
} 
Conhece alguma(s) experiência(s) didática(s) em prol de Letramentos acadêmicos, em LíNGUA ESTRANGEIRA, destinada(s) aos estudantes do curso de graduação coordenado por você (pode incluir iniciativas em conjunto com outras universidades)

Se respondeu SIM na questão anterior (questão 02), quais são as experiências relativas aos Letramentos acadêmicos que ocorrem no curso de graduação coordenado por você (incluindo iniciativas conjuntas com outras instituições) Marque todas as que se aplicam.

Cursos/disciplinas para estudantes de primeiro ano

Cursos/disciplinas para estudantes após o primeiro ano

Tutoriais

Centros de escrita / Laboratórios de escrita acadêmica

Programas articulados que incluem uma ou mais dessas iniciativas

Outro

Conhece alguma(s) experiência(s) didática(s) em prol de Letramentos acadêmicos em OUTRO CURSO DE GRADUAÇÃO de sua universidade ou instituição (independentemente se em língua portuguesa ou estrangeira)

Se sua resposta foi SIM na questão anterior (questão 03), descreva brevemente a(s) experiência(s). Explicite a(s) língua(s) envolvida na(s) experiência(s) e em qual(is) instituição(ões) ela(s) ocorre(m)

Conhece alguma(s) experiência(s) didática(s) em prol de Letramentos acadêmicos em OUTRA universidade ou instituição (independentemente se em língua portuguesa ou estrangeira)

Se sua resposta foi SIM na questão anterior (questão 04), descreva brevemente a(s) experiência(s). Explicite a(s) língua(s) envolvida na(s) experiência(s) e em qual(is) instituição(ões) ela(s) ocorre(m)

Quais são, em sua opinião, as maiores necessidades dos estudantes de graduação no Ensino Superior com relação ao desenvolvimento de práticas de Letramentos acadêmicos no curso coordenado por você?

Se desejar, faça outros comentários que julgue pertinentes sobre Letramentos acadêmicos

Fonte dos dados: pesquisadores do projeto Ações de Didatização de Gêneros em prol de Letramentos Acadêmicos

Na segunda ${ }^{12}$ fase, o aprofundamento das necessidades, demandas e motivações para encaminhamento de um plano de ação do estabelecimento de um Laboratório Integrado de Letramentos Acadêmicos - LILA será feito por meio de entrevistas semiestruturadas, conduzidas com base em um roteiro estruturante de perguntas abertas e com gravação em áudio e vídeo. A seleção dos entrevistados ocorrerá a partir das respostas obtidas pelos questionários, servindo para um aprofundamento e/ou esclarecimento dos dados obtidos.

Em relação à terceira fase, as ações coletivas do LILA serão de fato implementadas, sendo, concomitantemente, analisadas tanto no que concerne aos modelos de letramentos e capacidades de linguagem como em relação ao seu funcionamento e gerenciamento no que diz respeito a recursos humanos e material, estrutura física e possibilidades de parceria contínua entre as IES e outros laboratórios semelhantes. Propomos a identificação dos modelos de letramentos potencializados pelas atividades com base em Lea e Street (2014). Em relação às capacidades de linguagem, os critérios estão descritos em Cristovão e Stutz (2011). Essa

\footnotetext{
12 Por seu desenho sequencial, as etapas dois e três do projeto só poderão ser realizados após a tabulação dos dados obtidos com os questionários. Dessa forma, serão feitas emendas ao projeto original como forma de submeter as demais fases ao Comitê de Ética em Pesquisa.
}

Periódico Horizontes - USF - Itatiba, SP - Brasil - e020012 


\section{classificação poderá colaborar para possíveis (re)formulações em atividades e/ou materiais bem} como possíveis novas propostas de ações.

Como forma de síntese da proposta do projeto, o Quadro 3 apresenta o desenho da pesquisa:

Quadro 3 - Síntese do desenho de pesquisa do projeto Ações de Didatização de Gêneros em prol de Letramentos Acadêmicos

\begin{tabular}{|c|c|c|c|}
\hline Fase & Coleta ou geração de dados & Procedimentos de Análise de dados & Produto \\
\hline 1a. Fase & $\begin{array}{l}\text { Questionário virtual para mapeamento das } \\
\text { atividades/ações realizadas junto aos } \\
\text { responsáveis pelos laboratórios já } \\
\text { consolidados; } \\
\text { Questionário virtual para levantamento das } \\
\text { necessidades nas IES envolvidas no projeto; } \\
\text { Questionário virtual para levantamento de } \\
\text { necessidades e motivações para orientação } \\
\text { na percepção de acadêmicos das IES } \\
\text { envolvidas no projeto; } \\
\text { Análise de ementas das disciplinas ofertadas } \\
\text { em cursos de graduação e de pós-graduação } \\
\text { das IES envolvidas no projeto. }\end{array}$ & $\begin{array}{l}\text { Cálculos estatísticos para descrição } \\
\text { dos resultados com auxílio de } \\
\text { software como o SPSS com Escalas } \\
\text { Linkert ou SAS com coeficientes de } \\
\text { Person e de Spearman; } \\
\text { Análises interpretativas indutivas, } \\
\text { considerando particularidades } \\
\text { contextuais }\end{array}$ & $\begin{array}{l}\text { Artigo científico com o } \\
\text { mapeamento } \\
\text { construído; } \\
\text { Encaminhamentos } \\
\text { oficiais nas IES } \\
\text { envolvidas. }\end{array}$ \\
\hline 2a. Fase & $\begin{array}{c}\text { Entrevistas com participantes (gestores, } \\
\text { coordenadores de cursos e de programas e } \\
\text { acadêmicos) da primeira etapa da pesquisa } \\
\text { com vistas ao } \\
\text { aprofundamento/esclarecimento de } \\
\text { questões. }\end{array}$ & $\begin{array}{c}\text { Codificação com métodos de } \\
\text { primeiro ciclo (como a codificação } \\
\text { descritiva e a provisional) e de } \\
\text { segundo ciclo (como a teórica) com } \\
\text { base em Saldanha (2009); } \\
\text { Análise interpretativa dedutiva e } \\
\text { indutiva. }\end{array}$ & $\begin{array}{l}\text { Plano de ação do } \\
\text { estabelecimento de um } \\
\text { Laboratório Integrado } \\
\text { de Letramentos } \\
\text { Acadêmicos. }\end{array}$ \\
\hline 3a. Fase & $\begin{array}{l}\text { Observação participante (com tomada de } \\
\text { notas, protocolo e rubrica) sobre o } \\
\text { desenvolvimento de atividades realizadas } \\
\text { para o estabelecimento de um Laboratório } \\
\text { Integrado de Letramentos Acadêmicos entre } \\
\text { IES paranaenses; } \\
\text { Portfolio com Produções de alunos do } \\
\text { Laboratório de Letramentos Acadêmicos; } \\
\text { Entrevistas semi-estruturadas com } \\
\text { participantes de atividades como } \\
\text { workshops, palestras e cursos. }\end{array}$ & $\begin{array}{l}\text { Análise descritiva das ações de } \\
\text { estabelecimento de um Laboratório } \\
\text { Integrado de Letramentos } \\
\text { Acadêmicos; } \\
\text { Classificação dos tipos de } \\
\text { letramentos acadêmicos privilegiado } \\
\text { nas atividades desenvolvidas; } \\
\text { Identificação de capacidades de } \\
\text { linguagem nas produções iniciais e } \\
\text { finais de alunos atendidos; } \\
\text { Reconhecimento das percepções dos } \\
\text { participantes em relação aos } \\
\text { objetivos de promoção de } \\
\text { letramentos acadêmicos. }\end{array}$ & $\begin{array}{l}\text { Fundação e } \\
\text { estabelecimento de um } \\
\text { Laboratório Integrado } \\
\text { de Letramentos } \\
\text { Acadêmicos (LILA) entre } \\
\text { IES paranaenses; } \\
\text { Artigo(s) e capítulo(s) de } \\
\text { livro }\end{array}$ \\
\hline
\end{tabular}

Fonte: pesquisadores do projeto Ações de Didatização de Gêneros em prol de Letramentos Acadêmicos 
A implementação de um Laboratório Integrado de Letramentos Acadêmicos - LILA envolveria, a princípio, as três IES públicas paranaenses envolvidas no projeto. Contudo, estamos em busca de ampliação da rede de colaboração institucional, através da ampliação do número de IES participantes, com vistas a alcançarmos um maior envolvimento das universidades de todo o Estado. As ações previstas serão realizadas de modo coletivo e colaborativo, com o auxílio das tecnologias digitais, podendo abarcar: i) workshops (de até 16 horas na modalidade presencial e online) para a graduação, pós-graduação e/ou pesquisadores; ii) palestras para a graduação, pósgraduação e/ou pesquisadores; iii) cursos (de até 30 horas na modalidade presencial e online) para a graduação, pós-graduação e/ou pesquisadores; iv) formação de tutores para conduzirem atendimentos à graduação, pós-graduação e/ou aos pesquisadores; v) orientação individual pelos pesquisadores das diferentes áreas.

\section{Considerações finais}

A título de conclusão, apontaremos alguns desafios encontrados nessa primeira etapa de desenvolvimento do projeto, bem como possíveis ações para superá-los.

Como afirmamos anteriormente, a natureza do projeto é o trabalho em rede e colaborativo. Contamos, atualmente, com doze professoras pesquisadoras e dez estudantes envolvidos com projetos de Iniciação Científica, distribuídos por diversas regiões do estado do Paraná, sendo necessário para as reuniões o auxílio da tecnologia que, muitas vezes, não funciona adequadamente. Os encontros mensais online são permeados por problemas de conexão, gerando dificuldades de acompanhamento das reflexões teóricas e das decisões do grupo. Como forma de diminuirmos esse empecilho, foi criada uma sala virtual para postarmos comentários de leituras, compartilharmos textos teóricos e instrumentos de pesquisa, ou seja, como forma de promoção de interação virtual entre os membros do grupo.

O segundo ponto que merece destaque é a pouca adesão, até o momento, à participação do questionário da pesquisa. Foram enviados para o segmento da graduação, das três universidades, 255 convites, na segunda quinzena do mês de agosto. No início do mês de setembro, reenviamos o convite aos possíveis participantes, reforçando o pedido, sendo que, até o momento (início de outubro de 2019), obtivemos 14\% de respostas. Para alcançarmos 
números mais representativos, uma parte da equipe, formada por uma professora pesquisadora e alguns estudantes voluntários, enviará novamente um e-mail convite, além de entrar em contato telefônico com gestores das universidades solicitando auxílio na divulgação da pesquisa.

Por fim, ressaltamos uma terceira problemática relativa à análise das ementas das disciplinas dos cursos de graduação (também constante da etapa de análise de práticas e de demandas), uma vez que alguns Projetos Pedagógicos de Cursos (PPC) não estão disponíveis nos sites das universidades. Para termos acesso às ementas, estamos enviando e-mails aos coordenadores de cursos, bem como a gestores das universidades, solicitando os documentos para a análise.

Apesar das dificuldades iniciais, destacamos a produtividade da investigação realizada com pesquisadores provindos de diferentes contextos, enriquecendo as discussões e potencializando os resultados. Acreditamos, portanto, que as ações do LILA terão grande impacto nos estudos relativos aos Letramentos acadêmicos em universidades paranaenses.

\section{Referências}

BARTON, D.; HAMILTON, M. Local literacy: reading and writing in one community. London and New York: Routledge, 1998.

CRISTOVÃO, V. L. L. ; STUTZ, L. Sequências didáticas: semelhanças e especificidades no contexto francófono como L1 e no contexto brasileiro como LE. In: SZUNDY, P. T. C.; ARAÚJO, J. C.; NICOLAIDES, C. S.; SILVA, K. A. (Orgs.). Linguística aplicada e sociedade: ensino e aprendizagem de línguas no contexto brasileiro. Campinas: Pontes Editores2011.

DOLZ, J.; PASQUIER, A.; BRONCKART, J. P. L'acquisition des discours: emergence d'une compétence ou apprentissage de capacités langagières diverses. Etudes de Linguistique appliquée, París, n. 92, 1993.

DOLZ, J; SCHNEUWLY, B. Pour um enseignement de lóral: initiation aux genres formels à l'école. Paris: ESF Éditeurs, 1998.

DUDLEY-EVANS, T.; ST JOHN, M. J. Common-Core and Specific Approaches to the Teaching of Academic Writing. In: BELCHER, D.; BRAINE, G. (Orgs.) Academic Writing in a Second Language: Essays on Research and Pedagogy. Norwood: Ablex Publishing Corporation, 1995.

FIAD, R. S. A escrita na universidade. Revista da ABRALIN, v. Eletrônico, n. Especial, 2a parte, p. 
357-369. 2011. Disponível em: <http://www.abralin.org/revista/RVE2/14v.pdf.> Acesso em: 05 ago. 2019.

FIAD, R. S. Uma prática de letramento acadêmico sob análise. In: FIAD, R. S. (org). Letramentos acadêmicos: contextos, práticas e percepções. São Carlos: João \& Pedro Editores, 2016, p.201-222.

FISCHER, A. Sentidos situados em eventos de Letramentos na esfera acadêmica. Educação. Santa Maria, v. 35, n. 1, p. 215-228, maio/ago, 2010. Disponível em: <http://www.ufsm.br/revistaeducacao>. Acesso em: 07 ago. 2019.

GEE, J. P. Social linguistics and literacies: ideology in discourses. 2ed. London/ Philadelphia: The Farmer Press, 1996.

LEA, M. R.; STREET, B. V. Student writing in higher education: an academic literacies approach. Studies in Higher Education, n. 23 v. 2, 1998, p. 157-172.

LEA, M. R.; STREET, B. V. O modelo de Letramentos acadêmicos: Teoria e Aplicações. Filol. Linguíst. Port., São Paulo, v. 16, n. 2, p. 477-493, jul./dez. 2014. Disponível em <http://www.revistas.usp.br/flp/article/viewFile/79407/pdf_20>. Acesso em 05 jul. 2019.

MACHADO, A. R.; LOUSADA, E.; ABREU-TARDELLI, L. Resumo. Coleção Leitura e Produção de textos técnicos e acadêmicos. São Paulo: Parábola Editorial, 2004a.

Resenha. Coleção Leitura e Produção de textos técnicos e acadêmicos. São Paulo: Parábola Editorial, 2004b.

. Planejar gêneros acadêmicos. Coleção Leitura e Produção de textos técnicos e acadêmicos. São Paulo: Parábola Editorial, 2005a.

O Resumo Escolar: Uma Proposta de Ensino do Gênero. In: SIGNUM: Estud. Ling., Londrina, n. 8/1, p. 89-101, jun. 2005b.

. Trabalhos de Pesquisa. Coleção Leitura e Produção de textos técnicos e acadêmicos. São Paulo: Parábola Editorial, 2007.

MARINHO, M. A escrita nas práticas de Letramentos Acadêmicos. RBLA, Belo Horizonte, v. 10, n. 2, p. 363-386, 2010. Disponível em: http://www.scielo.br/pdf/rbla/v10n2/05.pdf. Acesso em: 10 jun. 2019.

MARINHO, M.; HENDGES, G. R. Produção textual na universidade. 4ạ.ed. São Paulo: Parábola Editorial, 2010.

MURRAY, L.; GLASS, B. Learning Development in Higher Education: Community of Practice or Profession? In: HARTLEY, P.; HILSDON, J.; KEENAN, C.; SINFIELD, S.; VERITY, M. (Orgs.). 


\section{HSE}
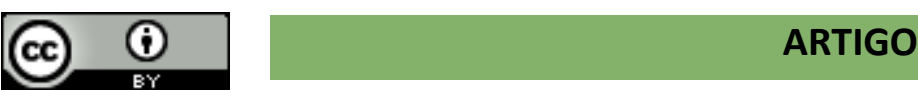

DOI: https://doi.org/10.24933/horizontes.v38i1.869

Universities into the 21st Century: Learning Development in Higher Education. Palgrave Macmillan: 2011.

PASQUOTTE-VIEIRA, E.; FIAD, R. S. Letramentos acadêmicos: entre práticas letradas acadêmicas e não acadêmicas. Linguagem \& Ensino, Pelotas, v.18, n.1, p. 125-150, jan./jun. 2015.

RINCK, F.; SILVA, J. Q. G.; ASSIS, J. A. Qual abordagem erigir para pensar as práticas de leitura e escrita na formação acadêmica e/ou na vida profissional? Scripta, Minas Gerais, v. 16, p. 7-16, 2012.

RINCK, F.; BOCH, F.; ASSIS, J. A. Apresentação. In: RINCK, F.; BOCH, F.; ASSIS, J. A. (orgs.). Letramento e formação universitária: formar para a escrita e pela escrita. Campinas: Mercado de Letras, 2015, p.11-25.

SALDAÑA, J. The coding manual for qualitative researchers. Los Angeles: CA: Sage. 2009.

STREET, B. V. Literacy in theory and practice. London: Cambridge University Press, 1984.

STREET, B. V.Letramentos sociais: abordagens críticas do letramento no desenvolvimento, na etnografia e na educação. São Paulo: Parábola Editorial, 2014.

STREET, B. V.Dimensões escondidas na escrita de artigos acadêmicos. Perspectiva, Florianópolis, v. 28, n. 2, p. 541-457, 2010.

TASHAKKORI, A.; CRESWELL, J. The new era of mixed methods. Journal of Mixed Methods Research, v.1, p. 3-7, 2007.

Recebido em outubro de 2019.

Aprovado em dezembro de 2019. 